\title{
Cultivating asparagus in Dadin-Kowa area of Gongola River Valley, Gombe State, Nigeria
}

\author{
Muhammad Bello Ibrahim ${ }^{1 *}$, Muhammad Siddique Depar², Muhammad \\ Waseem Kalroo ${ }^{2}$ and Arsalan Memon ${ }^{2}$ \\ 1. Department of Geography, University of Maiduguri-Nigeria \\ 2. PARC-Arid Zone Research Institute, Umerkot, Sindh-Pakistan \\ *Corresponding author's email: mbellodk@unimaid.edu.ng \\ Citation \\ Muhammad Bello Ibrahim, Muhammad Siddique Depar, Muhammad Waseem Kalroo and Arsalan Memon. \\ Cultivating asparagus in Dadin-Kowa area of Gongola River Valley, Gombe State, Nigeria. Pure and Applied \\ Biology. Vol. 10, Issue 1, pp334-340. http://dx.doi.org/10.19045/bspab.2021.100036
}

\begin{tabular}{llll}
\hline \hline Received: 06/06/2020 & Revised: 21/08/2020 & Accepted: 27/08/2020 & Online First: 25/09/2020 \\
\hline
\end{tabular}

\section{Abstract}

This study looks at the cultivation of Asparagus in the river Gongola valley around Dadin Kowa, Gombe state, Nigeria. The plant is a temperate crop and is usually consumed as vegetables in meals and also serves some medicinal purposes in some of the production areas. In recent times some parts of the tropics have started growing it with some degree of success. The study adopted a mixed methods research methodology. Data for the study was gathered from primary and secondary sources. Primary data was sourced over five years of field observations in the farms cultivating the plant in Dadin Kowa and purposive interviews with key informants cultivating the crop. The secondary data was sourced from relevant literature and the internet. Findings from the study suggests that over $90 \%$ success rate of Asparagus production in the tropics can be attained, once farmers make the right choice of farmlands and proper control of other variables like climate, availability of water and selecting the right specie to be grown. The study recommends more specific researches on cultivating the plant in the tropics and ways to encourage its consumption as a vegetable, improving plant production and for herbal medicinal purposes.

Keywords: Asparagus; Growing; Irrigation; Leaves; Spears; Tropics; Water

\section{Introduction}

Asparagus plant has been used as a vegetable and medicine, owing to its appealing taste, flavor, medicinal properties and more over the years in history. It is believed to be serving as an offering in olden Egyptian faiths dating to 3000 BC. In historical times, it was also known to be used in Syria and in old Spain. In mainland Europe, the Greeks and the Romans ate it fresh when in season, and dried the vegetable for use in winter when conditions are not favorable for its growth [1]. Asparagus, or garden asparagus, also commonly known as Sparrow grass, with the botanical name: Asparagus officinalis, is a spring vegetable, a flowering perennial plant species in the genus Asparagus and with lots of varieties that were successfully grown in the temperate and little in the tropics that do well like California 500, Mary Washington, Martha Washington, 
Giant Mary Washington, Carlim F1, and Vikima [2]. Asparagus officinalis is native to most parts of Europe, Northern Africa and Western Asia and is widely cultivated as a vegetable crop today is South Africa, East Africa and of recent West Africa promoting a wide range of plant broad production in the tropics [3]. The broad objective of the paper is to review Asparagus cultivation in the tropics and show how farmers in the Dadin Kowa area of Gombe state (Fig. 1), Nigeria produced the plant with remarkable degree of success, an experience that can be replicated in other parts of Nigeria to boost food production and employment in the agricultural sector, in addition to socioeconomic benefits.

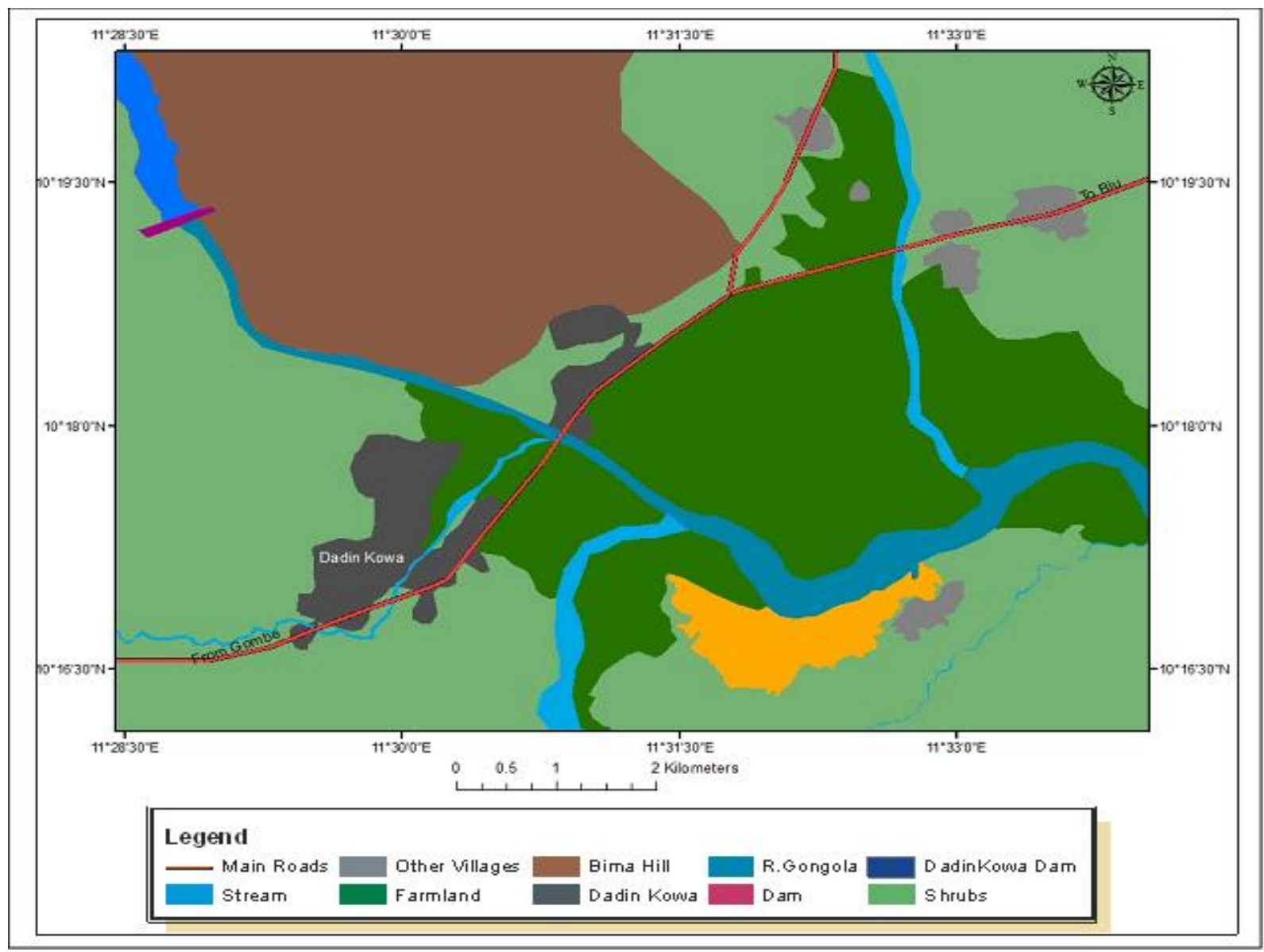

Figure 1. Study Area, showing Asparagus farms at the middle of the map, both sides of the river Gongola, marked green as fertile farmlands (Digitized map by: Mayomi, 2018)

\section{Materials and Methods}

The study adopted a mixed methodology, using quantitative and qualitative techniques for data generation. Field investigations were carried out from 2010 to 2018. Soil sample was taken from the farm and the descriptively analyzed data was used to give the fertility qualities of the soil. Interviews were conducted with key informants who happened to be farmers of Asparagus in the locality, their responses provided the primary data of the study, which was later themed and analyzed using content analysis. Secondary data from relevant and appropriate literature and the internet was reviewed, thematically analyzed, and used 
purposively for the study supporting findings in the study and corroborating with earlier observations by the pilot studies carried out by the researchers.

\section{The study area}

Dadin Kowa a town (Fig. 1) NE of Gombe the capital of Gombe State, Nigeria, lies between Longitude $11^{0} .31^{\prime} \mathrm{E}$ and Latitude $10^{\circ} .18^{\prime} \mathrm{N}$, with yearly average temperature of $26^{\circ} \mathrm{C}$ and rainfall of between $835 \mathrm{~mm}$ to $1200 \mathrm{~mm}$ per anum [4]. Asparagus plant, introduced in the study area around 1991 by Vegfru Limited, conventionally likes a $\mathrm{pH}$ of about 7, preferring a well-drained soil like the one in Gongola valley farm of Dadin Kowa, having a $\mathrm{pH}$ of 6.5 as established by a principal partner of Monocot \& Dicot Farms, who conducted a $\mathrm{pH}$ test within the two farm sites located in the area as corroborated by sampled soil test, carried out at the Department of Soil Science, University of Maiduguri (NE Nigeria) on $21^{\text {st }}$ February, 2018 showing a $\mathrm{pH}$ of $6.4, \mathrm{~N}$ of $0.20 \%, \mathrm{P}$ of $4.90 \mathrm{mg} / \mathrm{kg}$ and $\mathrm{K}$ of $0.50 \mathrm{Cmol}^{+} / \mathrm{kg}$ values respectively. The general textural class of the soil was found to be silt loam; a typical characteristic of soils found in river valleys similar to the study area.

\section{Cultivating asparagus in the tropics}

Asparagus (Asparagus officinalis) member of the Asparagaceae family and has been grown as a perennial plant and fodder for more than 2,000 years across the globe. The key to success with this vegetable is soil preparation, and given that Asparagus can go on producing for 20 years, it is worth doing well in the tropics for either subsistence or commercial basis, attaching various reasons commercial and medicinal uses as the case may be [5].

To be successful in cultivating Asparagus in the tropics, the farmer will need an area of well drained soil in good sunlight and expect to be tending the farmland for a good number of years, Asparagus can be in a farm for decades. Once established, this perennial vegetable will provide the farmer with a supply of shoots and leaves at harvesting time [6]. From the experiences of Dadin Kowa farmers, it gives a "sustainable income by selling the spears and products from the leaves and stems" [6] corroborating earlier studies on Asparagus in the tropical lands of Western Samoa, Fiji and Indonesia as a plant that provides farmers with sustainable income and for personal medicinal herbal uses [7].

The time to plant seeds, seedlings and crowns depends on the climate in the chosen area. Asparagus spears are heat-sensitive, but the plant is otherwise very adaptable to the subtropics and tropics after taking care of weather variables. Experiences of Asparagus grown in the tropical lands of Dadin Kowa (Fig. 1), in two different locations recorded yields, that are not as prolific as, in its ideal lands, but the plants do last as long as over a decade, as experimented by [8] who planted it in the year 2009 at "Exotic Multi Crops farms in the Gongola valley at Dadin Kowa in Gombe state" Nigeria, to date the farm is still 'harvesting from the initial plantings' in the farm. Plants are usually planted from May to July or in the tail end of the rains in late September to early October as the case may be, proved to "showing very encouraging foliage and presentable spears that can compete with those of temperate lands.

Transplanting seedlings and plant out crowns in most parts of the year had been practiced in the study area, from late May to mid-March; the Harmattan period of dusty and lower temperatures is between December to March, as a result of NE Trade winds blowing from the Sahara. The farmer should avoid periods of high temperatures in the dry and hot months of April to early June in the study area where temperatures can rise up to over $40^{\circ} \mathrm{C}$ [9]. 


\section{Some care and tending practices of asparagus}

Spears (Fig. 2) should be harvested in the first year after planting, a 'practice that was established very well by the defunct VEGFRU Limited' in Dadin Kowa [10]; allowing the spears to grow and fern-like foliage (called "ferns") to develop, then followed by flowering and setting of seeds. This will return nutrients and strength to the roots and help plants establish firmly for the couple of decades before being replaced, affirming experiences of the two farmers (KII) where they both confirmed "that stands of Asparagus in their farms have survived a decade and beyond, mainly harvesting its foliage and spears.

Ferns can reach a height of $1.1 \mathrm{~m}$, making it vulnerable to wind in periods with strong blowing wind incidences normally witnessed before setting of the rains in the study area. Every year when the spears start to appear, top-dressing with suitable soil is required, to guard against challenges by pest, diseases and destructive effects of sheeps, goats and cattles, as they very poorly patronize its foliage. Routine weeding to remove weeds is required, when herbicides are not used for weed control. Depending on nature of the farm, application of selective herbicides can be done with the help of Agricultural Extension Officers. It's vital to water regularly but deeply in drier months, so as to encourage strong root growth, especially in tropical dry lands of Sudan Savannah where the study area falls [11].

Asparagus plants are dioecious, meaning they can be male or female. Female plants produce red fruits and these should be removed when they appear (unless if a farmer want to collect the seeds), otherwise he may have hundreds of seedlings to weed out later as a result of unplanned germinations of dropped seeds. Some farmers advocate removing the female plants, believing they are less prolific than males. In real practice, the spears from female plants tend to be thicker but less prolific, while male spears are thinner (sometimes too thin) but more prolific [12]. Top-dress the bed with well-rotted manure and mulch with a thick layer of millet straw to keep weed growth to a minimum. Farmers in the study area, who grow asparagus, lets the chooks in to fertilize and scratch among the plants once the ferns have been removed, and only mulches later in the year when torrential rainfall starts between months of August and September. Farmers also grow other vegetables, like tomatoes and okra, in rows beside the asparagus on experimental basis, with remarkable success. The compost and 'manure added to the vegetables helps to feed the nearby asparagus and improve the quality of the shoots and leaves' [13].

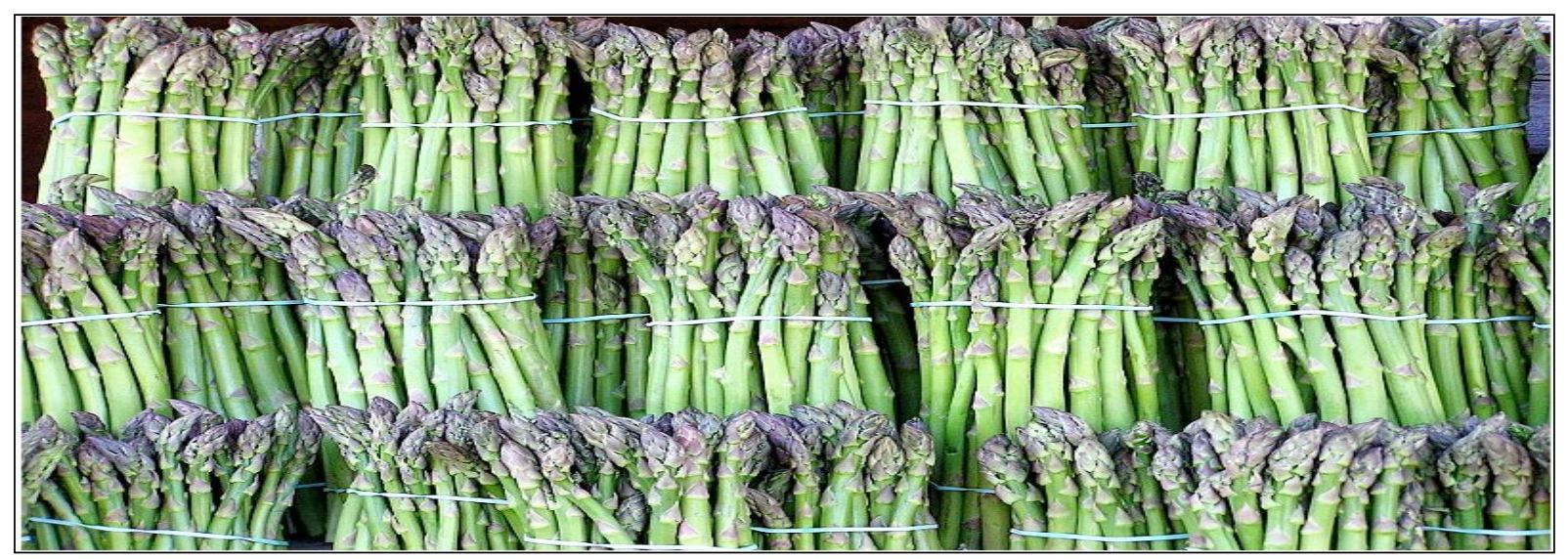

Figure 2. Spears of Asparagus, ready for market (Asparagus-lover.com, 2017) 


\section{Practices of Dadin Kowa farmers}

Growing Asparagus is not hugely labor intensive, as shown from interview responses, provided a farmer get the farmland and have some patience for the first couple of years to overcome some challenges. One-third $\left({ }^{1} / 3\right)$ of a hectare in the study area is "normally cultivated by two to three persons using manual labor" and an individual can handle that much when he uses simple farm machines and control weeds with chemicals [14]. The Asparagus spears can only be harvested for about 8 weeks a year, for those targeting the spears (Fig. 2), without weakening the plant, when the spears are left to grow on they become Asparagus fern. Looking after the farms very well is another characteristic of Dadin Kowa farmers, making asparagus fern well and farmers can be sure of another good crop the following year as corroborated by farmers elsewhere in temperate lands (Asparagus-lover.com, 2017). In the study area, Asparagus cultivation is "mostly targeting harvesting well grown leaves and spears for medicinal uses (Fig. 3), a practice that involves drying the spears and the leaves, thereafter grind it to powder for oral medicinal administration in drinks" or flavorings of meals as seen by the Nigeria regulatory agency, National Food and Drug, Administration and Control (NAFDAC) certified product of Monocot and Dicot Limited, Dadin Kowa [15].

Planting Asparagus crowns (as the root system is commonly known) is the usual way of establishing an asparagus bed. The terms asparagus plant and crown are widely used and sometimes these are referred to as Asparagus roots and are used interchangeably as can be obtainable in the literature. Asparagus seeds, though mostly called or referred to asparagus crowns and plants can be grown asparagus from seed as well. In fact, this is how the initial growers raised the crowns, which most potential farmers "from elsewhere buy and plant in new farms as experienced in the Dadin Kowa [16].

For the average casual farmer though planting crowns is the way forward, he can do good by planting the seeds, which will usually take longer time to mature and be ready for harvesting. The Asparagus plant is grown all year round in Dadin Kowa farms, in the dry season when rains had stopped falling, irrigation is next option for watering the farms either using sprinklers or watering in between the rows with frequency of watering seldom in all rainy months of the dry season and once in a week in the months of March to May [17].

The Dadin Kowa farmers of Asparagus were really dogged in its cultivation. In the early years, when the plant was "first introduced in the area by Vegfru Limited in 1991 and the produce was usually exported to the UK" [18]. Findings suggest that farmers are better off in producing at least the Mary Washington variety of Asparagus all year round. Challenges over the years in the production borders on right choice of farms (soils), correct timing of planting, mastering pruning and harvesting of spears, seeds and leaves, and sourcing for a readily available market for the various products of the vegetable [19]. When efforts by Vegfru Limited failed to sustained exports, the whole idea of its production in the Gongola Valley was jettisoned, only to be picked up in 2001 by a former worker of the now comatose Vegfru Limited, in partnership with a financier established the first Asparagus farm in a fertile floodplains of the river Gongola valley. This initiative was a success story, in that the crop flourishes to date, but its marketing was seriously challenged by consumers that are difficult to be readily found except within the few expatriate Europeans and Americans in Abuja, Port Harcourt and Lagos axis. They resorted to "simple marketing through 
drying the spears and the leaves, and reducing it to powder for medicinal purposes, normally for diseases associated with urinary track infections and mild kidney related diseases [20]. Today as research interview respondents and field observations revealed, Asparagus cultivation in the Gongola River valley of Dadin Kowa area is purposefully done to "cater for herbal medicinal purposes rather than used as part of daily menus" of households [20].

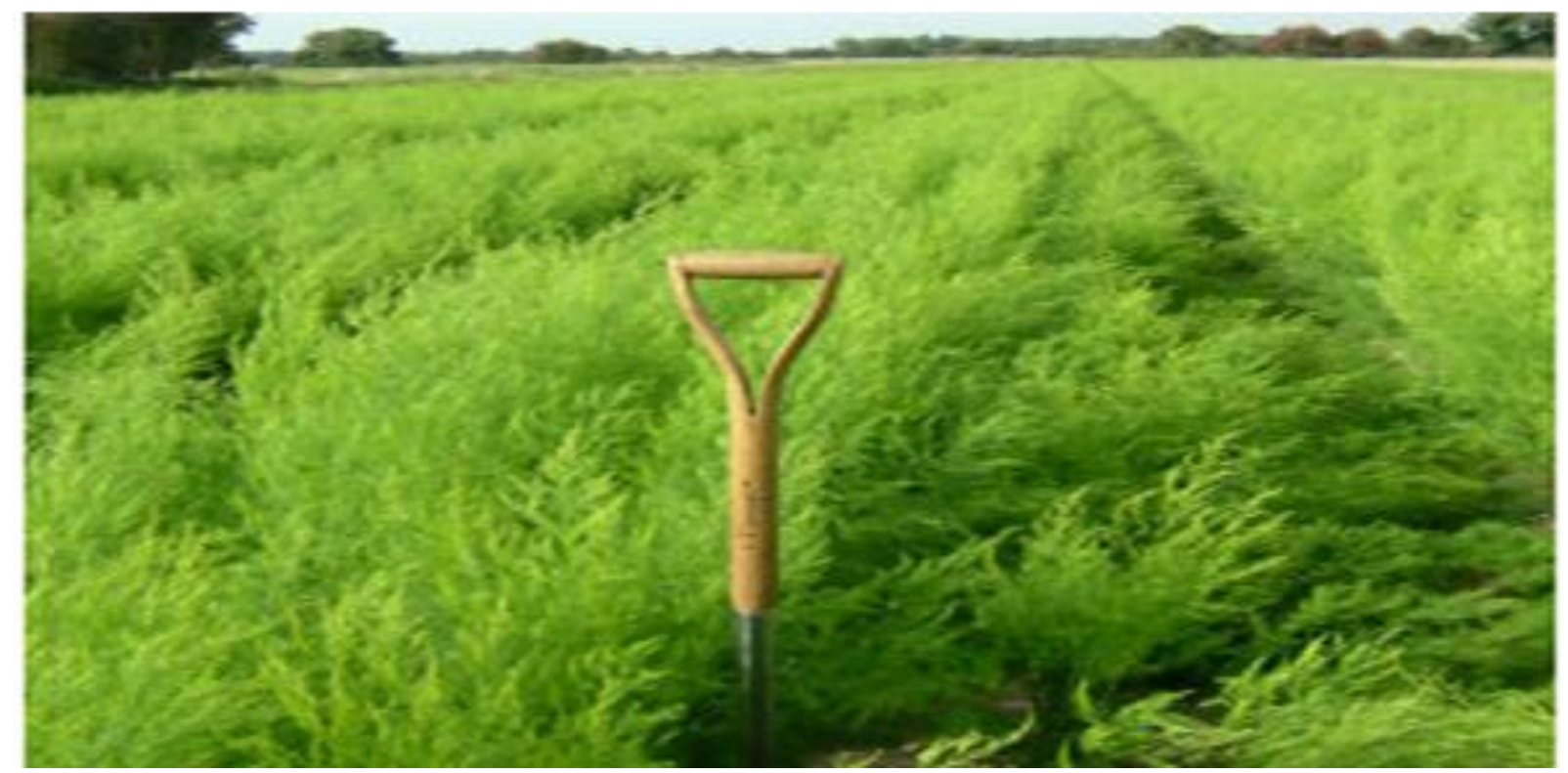

Figure 3. The Asparagus Farm, fully in leaves. (Asparagus-lover.com, 2017)

\section{Conclusion}

Asparagus plant (Mary Washington) is well grown in the Gongola valley farmlands of Dadin Kowa area of Gombe state, NE Nigeria. Farmers got introduced to the plant through activities of the defunct Vegfru Limited, an agro-allied company that produces vegetables and fruits on commercial basis and adds value to it through processing and marketing to consumers within Nigeria and in the United Kingdom (UK). The plant, despite acceptability issues in local menu, has a very good prospect in terms income generation and adaptability to the climatic conditions of the selected sites in the study area. With further research studies and proper planning to control many variables, the cultivation of Asparagus can be enhanced and farmers can be contributing their meager quota in its production in the NE region and the country at large to boost food supply and increase income to farmers through various socioeconomic activities associated with its cultivation.

\section{Authors' contributions}

Conceived and performed the experiments: MB Ibrahim, Provided technical support and revised paper: MS Depar, Identified the plant species: MW Kalroo, Wrote the paper: A Memon.

\section{Acknowledgement}

The authors acknowledge PARC-AZRI for providing facilities of identification of Asparagus plant and the completion of this research work.

\section{References}

1. Woodward P (2010). Asparagus. Wikipedia.org, Accessed 11.12.2017

2. Ayuba HK (2005). Environmental science: an introductory text. Apani Pub Kaduna. 
3. Agboola AA (1979). An agricultural atlas of Nigeria. Oxford University Press, Ibadan.

4. Ibeje AO \& Okoro BC (2013). Shortterm forecasting of Dadin-Kowa reservoir inflow using Artificial Neural Network. Int J Eng \& Sci 2(6): 63-73

5. Anonymous (2017). Asparaguslover.com www.asparaguslover.com/growing-asparagus.

Accessed 12.12.2017

6. Deputy J (1999). Asparagus. Home Garden Vegetables HGV-9 CTAHR, University of Hawaii at Manoa, Honolulu.

7. Nichols MA (1992). Asparagus production in the tropics. Acta Hortic 292: $149-154$

8. Gardenate (2010). Growing Asparagus. In www. Gardenate.com Retrieved 08/04/20

9. Mubarok S (2018). Cultivating of Asparagus as an annual crop in the tropics: growth, spear yield and size of two cultivars harvested at different plant age. Acta Hortic 123(23). 159-164

10. Asparagus officinalis (2019). General information and propagation. In www.tropical.theferns.info Retrieved 10/04/20

11. Shahid M \& Rao NK (2011). Performance of Asparagus under the desert conditions of Arabian Peninsula: A pilot study. J Appl Hort 13(1): 27-29

12. Prota (2018). Asparagus officinalis. In www.uses.plantnet-project.org Retrieved 10/04/20

13. Green J (2018). Asparagus plant temperature range. In www.homeguides.sfgate.com Retrieved $14 / 04 / 20$

14. Harrington J (2007). How to grow Asparagus from rootstock. In www.homeguides. sfgate.com/growasparagus.

15. Miller, L. (2019). Nine different types of

Asparagus.

In www.elist10.com/different-types-ofasparagus.

16. Gavin S (2005). Long term food prospects for Africa. In Report of the NEST Agriculture Summit 2005.

17. Cantaluppi CJ (1994). Asparagus: a small-scale agriculture alternative. In www.sfp.ucdavis.edu

18. Lintu, L. (2009). An introduction to selected FAO related non-wood forest products. In $w w w$.fao.org/docrep

19. UBRBDA (2017). Upper Benue River Basin Development Authority, Area Office Weather Station Records, Dadin Kowa

20. Gwani (2016) Vegfru Limited 1991 Yearly Report. 